\title{
Effect of oral melatonin on plasma growth hormone concentration in rhesus monkeys (Macaca mulatta)
}

\author{
Ghulam Jaffar Kanhar ${ }^{1}$ and Samiullah Soomro ${ }^{2 *}$ \\ 1. Department of Animal Sciences, Quaid-i-Azam University, Islamabad, Pakistan \\ 2. Department of Zoology, University of Sindh, Jamshoro, Pakistan \\ *Corresponding author's email: samiqau373@gmail.com \\ Citation \\ Ghulam Jaffar Kanhar and Samiullah Soomro. Effect of oral melatonin on plasma growth hormone concentration in \\ rhesus monkeys (Macaca mulatta). Pure and Applied Biology. Vol. 10, Issue 4, pp1278-1286. \\ http://dx.doi.org/10.19045/bspab.2021.100133
}

\begin{tabular}{llll}
\hline \hline Received: 10/12/2020 & Revised: 19/02/2021 & Accepted: 25/02/2021 & Online First: 05/03/2021 \\
\hline
\end{tabular}

\section{Abstract}

This study has been carried out to discover the cause of exogenous melatonin on plasma growth hormone concentration (PGHC) in four adult Macaca mulatta (rhesus monkeys). To inspect the result of solitary dose $(5 \mathrm{mg})$ of exogenous melatonin on PGHC four adult individual of Macaca mulatta with mean body weight $8.62 \pm 1.05$ were utilized. Sharp decrease in PGHC was noticed at 105 minutes $3.13 \pm 0.88 \mathrm{mIU} / \mathrm{L}$, and 120 minutes $2.86 \pm 0.87 \mathrm{mIU} / \mathrm{L}$. The growth hormone levels recorded after every 15 -minutes showed gradual decrease with the advance time. Growth hormone levels regressed negatively with time $(b=-0.9202 \pm 0.071)$. Extremely imperative reduction have been noticed through regression analysis in growth hormone levels with the advance in time $\left(\mathrm{F}_{(1,6)}=163.5, \mathrm{P}<0.0001\right)$. Results of this study supports that melatonin sharply increases plasma growth hormone concentrations for short time and then starts decreasing.

Keywords: Melatonin, Oral, PGHC, Plasma, hormone, exogenous

\section{Introduction}

For some 50 years ago pineal gland was known as rudimentary gland in the body. Basically, pineal gland recognized about 2000 years ago [1]. In 1958, circumstances altered when Aaron Lerner and his colleagues discovered melatonin (pineal active substance) with its chemical structure "N acetyl-5-methoxytryptamine" [2, 3]. MT1, MT2 and MT3 are known as three types of melatonin receptors which were discovered on the basis of their molecular structures [4, 5]. Along with some other sides, melatonin also produced inside the retina and pineal gland [6]. Due to strong association of pineal and reproductive system in animals the reproduction in gonadal axis normalized by melatonin [7]. It has been investigated that for the physiological development of the normal puberty melatonin perform a key function $[7,8]$. Abnormal fluctuations in the level of melatonin linked with delayed and precocious puberty $[9,10]$. Monkeys and humans are non-seasonal breeders so the pineal played major role to regulate the reproductive physiology and neuroendocrine regulation of puberty [11]. The somatotrope cells of the anterior pituitary produced Growth hormone $(\mathrm{GH})$ which is a protein made up of 191 amino acids [12]. In prepubescent children the significant reduction in $\mathrm{GH}$ has been figure out while in 
adult there is no any effect on the level of GH by melatonin treatment [13, 14]. In comparison, additional research suggests that in normal humans there is little increase in the level of basal Growth hormone by large dose of exogenous melatonin [15]. In rodents, clear inhibitory results of melatonin injections have been observed [16]. Contrastingly, some results showed that IGFI and circulating concentrations of growth hormone were increasing by evening melatonin injections [17]. Number of studies has been carried out to show the effect of melatonin harmone in various organisms with an assortment of aspects $[7,8,11,13$, $14,19,23,25]$ but no significant study has been carried out to explore the effects of exogenous melatonin on plasma growth hormone concentration correlated with time and treatment. Present study has been conducted to show the effect of exogenous melatonin administration on plasma growth hormone concentration in adult male rhesus monkeys (Macaca mulatta).

Materials and Methods

In this study, experimental study of four adult male rhesus monkeys (8-10 years age) was performed. Each animal was assigned with particular number: 0702, 0703, 0704 and 0705. Dental formula was used to calculate the ages of animals [18]. During experiment, body weight of used animals was weighed as ranged from 6.8-10.5 (kg). In Primate Facility, each individual was housed in specific cage and sustained in standard colony circumstances at Quaid-i-Azam University, Islamabad. Vegetables and fresh fruits were supplied to those animals as standard monkey food. Water availability was facilitated ad-libitum. Before the beginning of experiment (1 month ago) the appetite of the animals was monitored. All individuals utilized in this experiment were capable to eat their food within limited time of 5-10 minutes. The food protocol was maintained under proper time schedule (Fruits, boiled potatoes, eggs and bread at 6:00am, 9:00am, 11:00am and 1:00pm respectively) on daily basis. All animals were provided diet on behalf of their body weight.

\section{Pharmacologic agents}

Two drugs were utilized in the present study: First, Ketamine hydrochloride (Ketavet; Park-Davis, Berlin, FRG) and Second, Melatonin (N-acetyl-5-methoxytryptamine) (5 mg).

\section{Experimental protocol}

Bleeding started from -30 minutes and melatonin was given orally at 0 minute (Fig. $1)$.

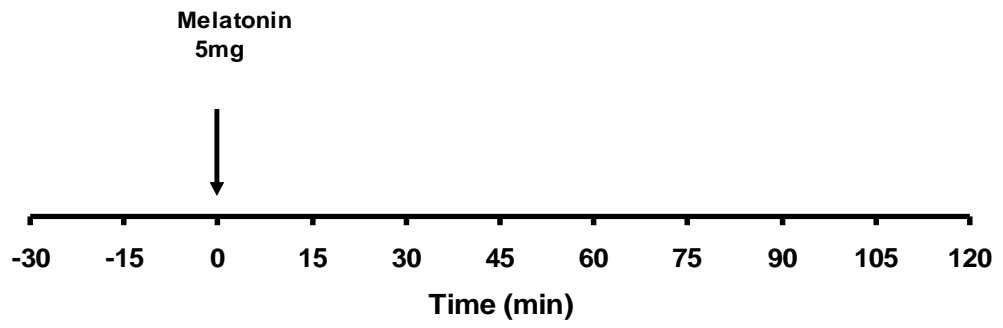

Figure 1. Experimental Protocol showing the bleeding time before and after melatonin treatment

\section{Chair restraining method}

Before 8 weeks of beginning of the experimental study the animals were adapted for chair restraining. On the chair, each animal was restrained for two hours on daily basis. Animals were also taught to get their foodstuff although chair restrained. Ketamine hydrochloride $(5 \mathrm{mg} / \mathrm{kg} \quad \mathrm{BW})$ was used 
intramuscularly in order to create effortlessness situation to fix and remove from the chair animals were knocked out.

\section{Catheterization}

Prior to handle, $5 \mathrm{mg} / \mathrm{kg}$ of Ketamine was used to anaesthetize animals. Beginning of sampling (before 60 minutes) in the sephanous vein a Teflon cannula was introduced and animals were restrained to the chair. Through a butterfly tubing ( $20 \mathrm{~g}$ weight and $300 \mathrm{~mm}$ length) the terminal part of the cannula was affixed to a syringe. The given amount of ketamine was enough to halt status of the animal but not enough to induce narcosis.

\section{Bleeding}

After every 15 minutes, sequential blood samples $(2.0 \mathrm{ml}$ of each) were achieved before single dose of melatonin orally $(5 \mathrm{mg})$. The blood samples were achieved in hepranized syringes following melatonin administration and the same volume (5
IU/ml) of hepranized saline inserted in tubing. Whole bleeding was taken out during 9:00-10:00 am and for 10 minutes at 3000 rpm samples was centrifuged and extracted plasma was preserved at temperature of $15^{\circ} \mathrm{C}$.

Immunoradiometric (IRMA) assay for growth hormone

For the proper analysis of data mean and standard error were calculated. For the comparison of mean student's $t$ test was applied. Regression analysis of variance was used to show the plasma Growth hormone concentrations regress on time following treatment with melatonin.

\section{Results}

Results of this designed study examined the response of exogenous melatonin in rhesus monkeys (male adult) on plasma growth hormone concentrations. Mean body weight $(\mathrm{kg})$ of all the four monkeys studied shown out in (Table 1).

Table 1. Mean body weight $(\mathrm{kg})$ of rhesus monkeys (male adult $\mathrm{n}=4$ )

\begin{tabular}{|c|c|}
\hline Monkey No. & Body weight (kg) \\
\hline 0702 & 9.3 \\
\hline 0703 & 5.7 \\
\hline 0704 & 10.4 \\
\hline 0705 & 9.1 \\
\hline Mean \pm SEM & $8.62 \pm 1.05$ \\
\hline
\end{tabular}

Effect of exogenous melatonin on mean plasma growth hormone concentration (mIU/L) in adult male rhesus monkeys (Macaca mulatta)

Prior and later to single dose of melatonin (5mg) administration PGHC (mIU/L) mentioned in (Table $2 \&$ Fig. 2). Melatonin treatment was given to four adult male rhesus monkeys. Plasma growth hormone concentration was recorded before treatment with melatonin. Mean concentration at -30 minutes for the four monkeys was $4.95 \pm 0.67$ $\mathrm{mIU} / \mathrm{L}$. The plasma growth hormone concentration increased at -15 minutes $5.27 \pm$
$1.04 \mathrm{mIU} / \mathrm{L}$, but this decreased at 0 minute $4.51 \pm 0.87 \mathrm{mIU} / \mathrm{L}$. Melatonin was administered orally with a dose of $5 \mathrm{mg}$ to the four monkeys at 0 minute. The rapid increasement $(8.83 \pm 2.79 \mathrm{mIU} / \mathrm{L})$ has been recorded in mean PGHC after 15 minutes of treatment. This increase in growth hormone concentration (GHC) was not considerably dissimilar from that at 0 minute $\left(t_{(6)}=1.18\right.$; $\mathrm{P}>0.1)$. There was a slight decrease at 30minutes time $8.71 \pm 2.81 \mathrm{mIU} / \mathrm{L}$ but at 45 minutes time there was sudden decrease in concentration $7.65 \pm 3.22 \mathrm{mIU} / \mathrm{L}$. A steady decrease in plasma growth hormone 
concentration was observed at 60 minutes $6.54 \pm 2.97 \mathrm{mIU} / \mathrm{L}, 75$ minutes $5.62 \pm 3.11$ $\mathrm{mIU} / \mathrm{L}$, and 90 minutes $5.42 \pm 2.46 \mathrm{mIU} / \mathrm{L}$ after treatment. Sharp decrease in plasma growth hormone concentration was observed at 105 minutes $3.13 \pm 0.88 \mathrm{mIU} / \mathrm{L}$, and 120 minutes $2.86 \pm 0.87 \mathrm{mIU} / \mathrm{L}$.

Table 2. PGHC in Rhesus monkey (male adult) prior and later single dose of melatonin (5mg) administration

\begin{tabular}{|c|c|c|c|c|c|c|}
\hline \multirow{2}{*}{$\begin{array}{c}\text { Time } \\
(\text { minute) }\end{array}$} & \multicolumn{7}{|c|}{ Plasma Growth hormone concentration } & \multicolumn{2}{c|}{ (mIU/L) } & \multicolumn{2}{c}{ Mean } \\
\cline { 2 - 5 } & \multicolumn{7}{|c|}{$\begin{array}{c}\text { Monkey No. } \\
\mathbf{0 7 0 2}\end{array}$} & $\mathbf{0 7 0 3}$ & $\mathbf{0 7 0 4}$ & $\mathbf{0 7 0 5}$ & \\
\hline-30 & 4.77 & 3.26 & 5.27 & 6.52 & 4.95 & \pm 0.67 \\
\hline-15 & 3.49 & 3.73 & 7.97 & 5.89 & 5.27 & \pm 1.04 \\
\hline 0 & 3.09 & 2.99 & 6.519 & 5.43 & 4.51 & \pm 0.87 \\
\hline 15 & 4.87 & 5.27 & 16.91 & 8.29 & 8.83 & \pm 2.79 \\
\hline 30 & 4.97 & 4.79 & 16.78 & 8.29 & 8.71 & \pm 2.81 \\
\hline 45 & 4.11 & 3.87 & 17.28 & 5.33 & 7.65 & \pm 3.22 \\
\hline 60 & 4.39 & 3.50 & 15.42 & 2.83 & 6.54 & \pm 2.97 \\
\hline 75 & 2.01 & 2.61 & 14.92 & 2.95 & 5.62 & \pm 3.11 \\
\hline 90 & 1.92 & 4.20 & 12.68 & 2.89 & 5.42 & \pm 2.46 \\
\hline 105 & 1.53 & 3.44 & 5.50 & 2.07 & 3.13 & \pm 0.88 \\
\hline 120 & 1.38 & 3.62 & 4.97 & 1.45 & 2.86 & \pm 0.87 \\
\hline
\end{tabular}

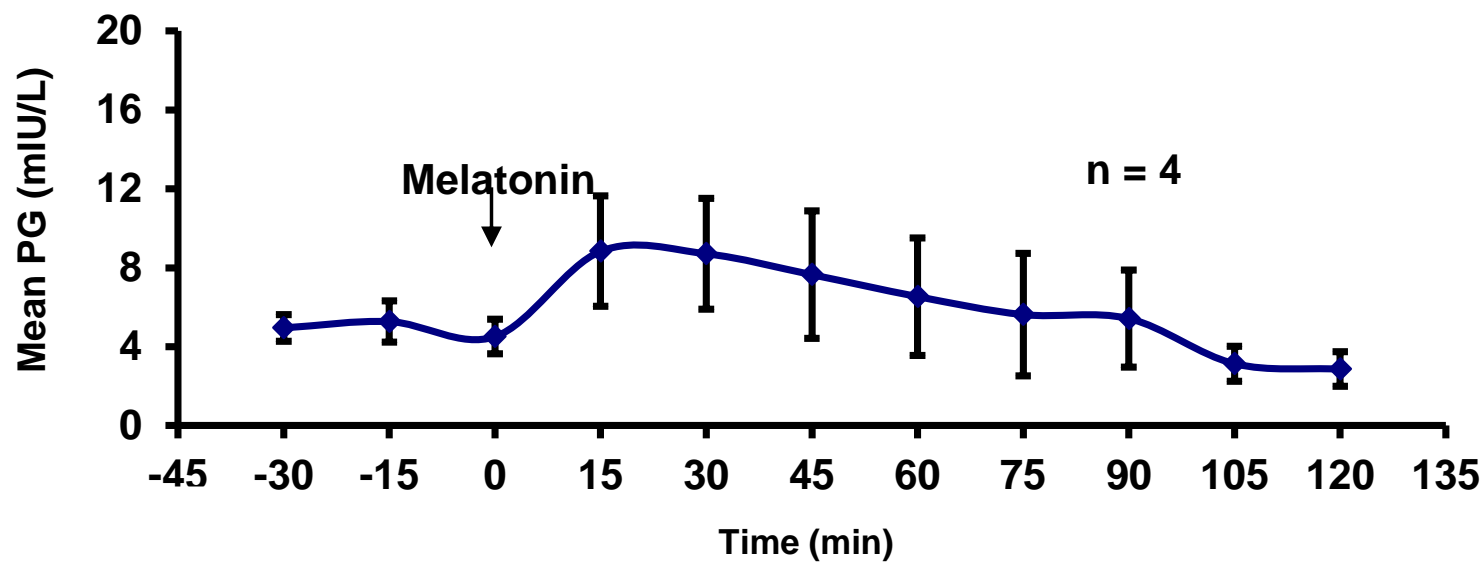

Figure 2. Change in mean ( \pm SEM) plasma Growth hormone concentration (mIU/L) in rhesus monkey $(n=4)$ prior and later single dose of melatonin $(5 \mathrm{mg})$ administration

Growth hormone concentration (mIU/L) at various segments of treatment period Mean plasma growth hormone concentration (mIU/L) (Table 3) in the four monkeys before treatment in the segment -30 to 0 minute was $4.86 \pm 0.87 \mathrm{mIU} / \mathrm{L}$. After melatonin treatment $(5 \mathrm{mg})$ the highest mean concentration of plasma growth hormone was 
observed in the segment from 15 to 45 minutes $8.40 \pm 1.56 \mathrm{mIU} / \mathrm{L}$. This increase in concentration was significantly higher compared to before treatment segment $\left(t_{(22)}=\right.$ 2.18; $\mathrm{P}<0.05)$. There was a decrease in PGHC in segment from 60 to 90 minutes 5.86 $\pm 1.50 \mathrm{mIU} / \mathrm{L}$, but this decrease was not considerably dissimilar compared to segment 15 minutes to 45 minutes $\left(t_{(22}=1.18\right.$; $\mathrm{P}>0.20)$. The lowest mean concentration of plasma growth hormone was observed in the segment 105 minutes to 120 minutes $3.00 \pm$ $0.57 \mathrm{mIU} / \mathrm{L}$ but this was not significant decrease compared to segment 60 minutes to 90 minutes $\left(t_{(18)}=1.78 ; \mathrm{P}>0.20\right)$. Segment 105 minutes to 120 minutes compared to segment 15 to 45 minutes shows highly significant decrease in plasma growth hormone concentration $\left(t_{(18}=3.29 ; \mathrm{P}<0.01\right)$. After 15 minutes of treatment with melatonin the highest growth hormone levels $8.83 \pm$ $2.79 \mathrm{mIU} / \mathrm{L}$ was recorded. The growth hormone levels recorded after every 15 minutes showed gradual decrease with the advance time. Growth hormone levels regressed negatively with time $(b=-0.9202 \pm$ $0.071)$. It has been noticed that regression analysis of variance determined the very considerable decrease in growth hormone levels with the advance in time $\left(F_{(1,6)}=163.5, P<0.0001\right)$ (Fig. 3).

Table 3. Plasma growth hormone concentration (mIU/L) prior and later single dose of melatonin (5mg) treatment at different segments in Rhesus monkey

\begin{tabular}{|c|c|c|c|c|}
\hline \multirow{2}{*}{$\begin{array}{c}\text { Time } \\
\text { (minute) }\end{array}$} & Prior Treatment & \multicolumn{3}{|c|}{ Later Treatment } \\
\cline { 2 - 5 } & -30 to 0 & 15 to 45 & 60 to 90 & 105 to 120 \\
\hline Mean \pm SEM & $4.86 \pm 0.51$ & $8.40 \pm 1.54$ & $5.86 \pm 1.50$ & $3.00 \pm 0.57$ \\
\hline
\end{tabular}

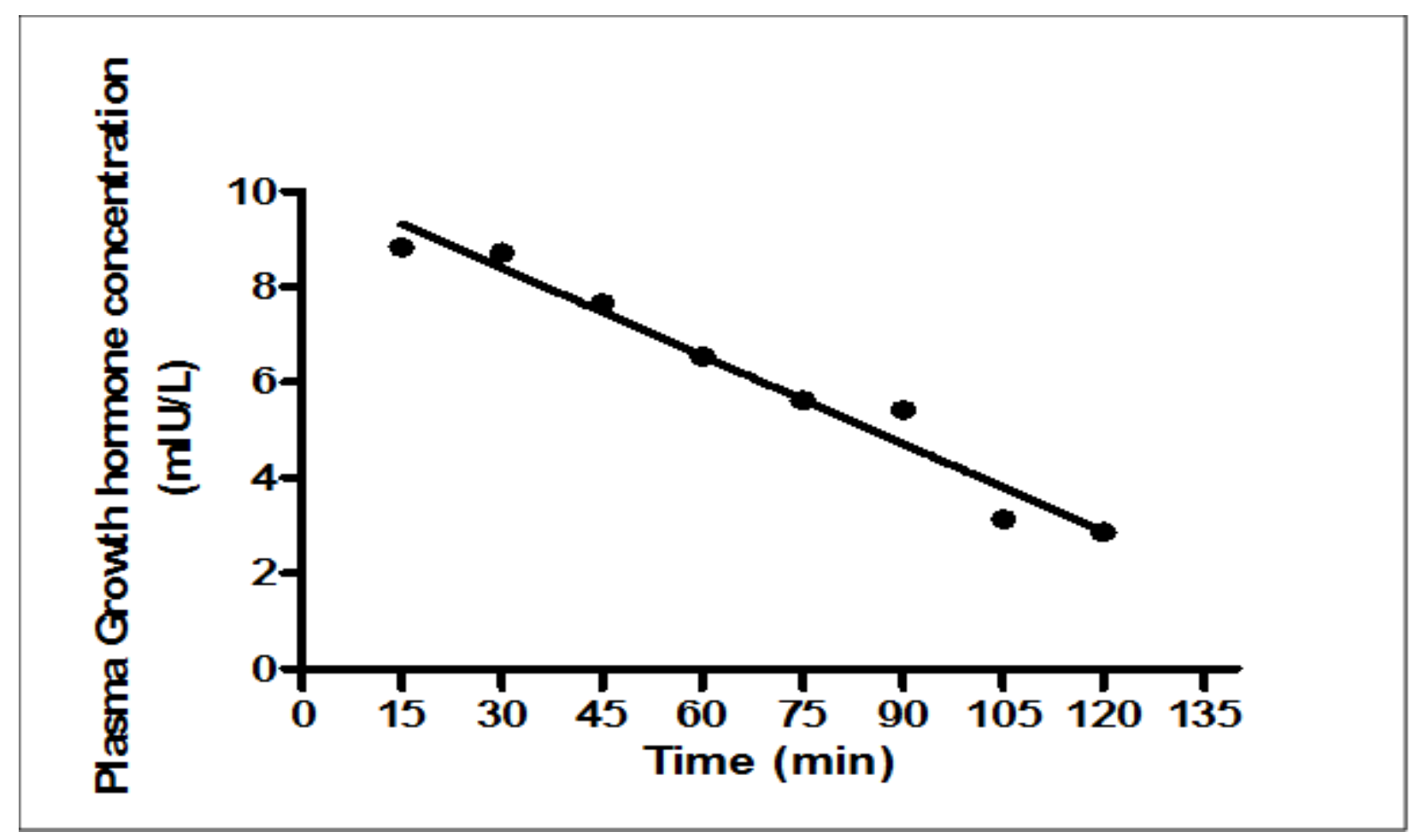

Figure 3. Calculated regression line indicating plasma Growth hormone concentration (mIU/L) against time after treatment 
Effect of exogenous melatonin on individual plasma growth hormone concentration $(\mathrm{mIU} / \mathrm{L})$ in adult male rhesus monkeys (Macaca mulatta)

Individual plasma growth hormone concentration $(\mathrm{mIU} / \mathrm{L})$ prior and later single dose of melatonin $(5 \mathrm{mg})$ administration showed in (Table 2 \& Fig. 4a, b). Melatonin treatment was given to four adult male rhesus monkeys individually. Plasma growth hormone concentration was recorded before treatment with melatonin. Individual plasma growth hormone concentration of animals
0702, 0703, 0704, and 0705 at 0 minute timing was 3.09, 2.99, 6.51 and 5.43 (mIU/L) respectively. Melatonin was administered orally with a dose of $5 \mathrm{mg}$ to all four monkeys at 0 minute. After 15 minutes of treatment rapid increase in PGHC to 4.87, 5.27, 16.91 and 8.29 (mIU/L) has been recorded respectively, the level of plasma growth hormone concentration (mIU/L) raised upto 30 minutes in all individuals, then it started decreasing slowly in all individuals from 45 to 120 minutes and reached to $1.38,3.62,4.97$ and $1.45(\mathrm{mIU} / \mathrm{L})$ respectively.
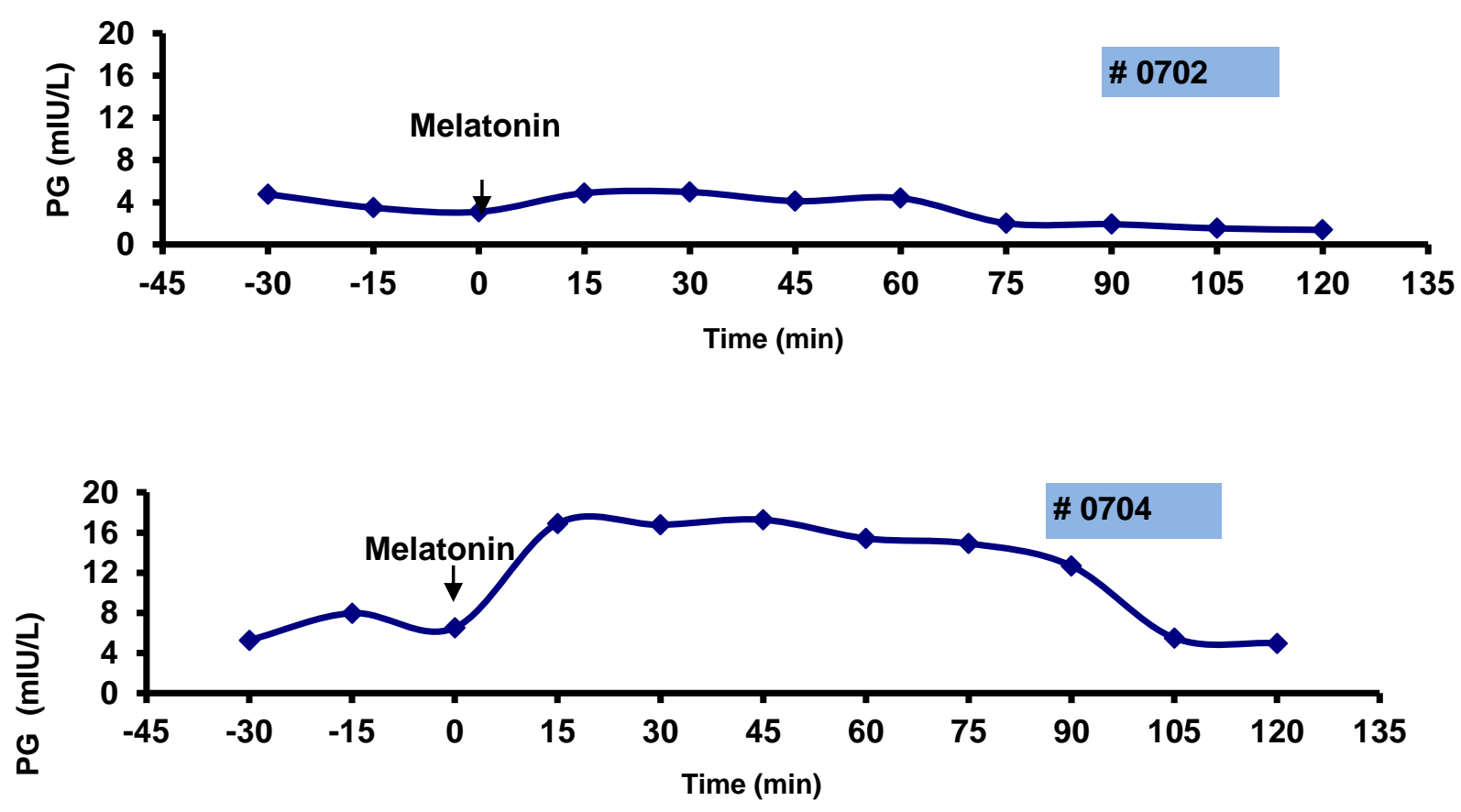

Figure 4. (a) Differentiation in individual PGHC (mIU/L) in rhesus monkey prior and later single dose of melatonin (5mg) administration. [PG: Plasma Growth Hormone Concentration (mIU/L)] 

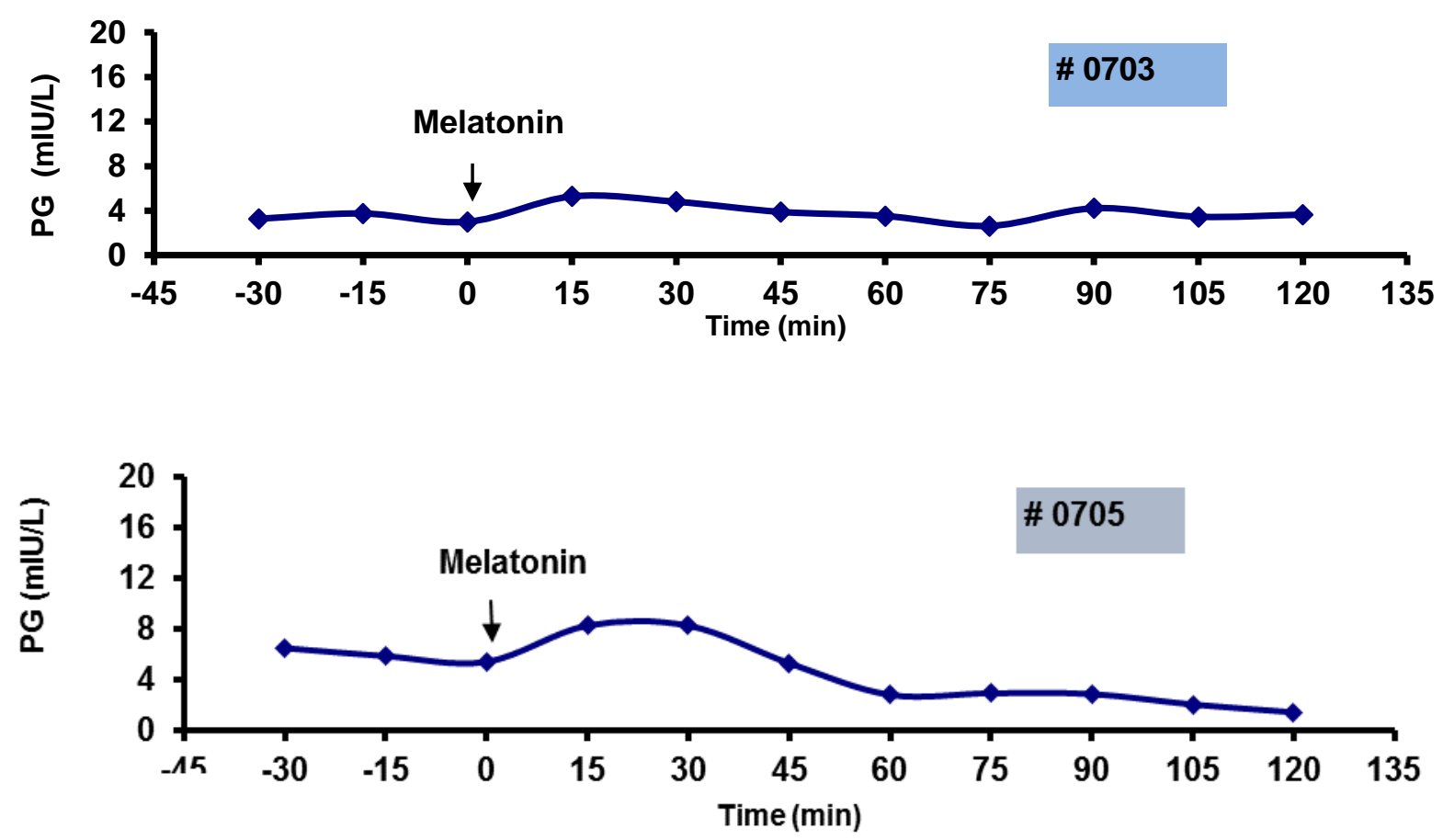

Figure 4. (b) Differentiation in individual PGHC (mIU/L) in rhesus monkey prior and later dose of melatonin (5mg) administration. [PG: Plasma Growth Hormone Concentration (mIU/L)]

\section{Discussion}

Male rhesus monkeys (Macaca mulatta) were utilized by Rizvi and team [19, 20] with body weight $(9.1 \pm 0.46 \mathrm{~kg})$ for the study of growth hormone (released in pituitary) feedback to graded prescribed amount (dose) of GHRH (Growth hormone-releasing hormone) and they have reported basal plasma Growth hormone concentration to be $10 \cdot 1 \pm 1 \cdot 0 \mathrm{mU} / \mathrm{l}$. However, in this study mean basal GHC was $4.95 \mathrm{mIU} / \mathrm{L}$ with a range 2.99-7.95 $\mathrm{mIU} / \mathrm{L}$. In the present study plasma Growth hormone concentration (mIU/L) was measured between 10:30 am and 2:30 pm before and after melatonin treatment. Before melatonin treatment mean concentration of growth hormone at -30 minutes was $4.95 \pm$ $0.67 \mathrm{mIU} / \mathrm{L}$. Melatonin was administered at 0 minute about 11:30 am, after 15 minutes of melatonin treatment there was considerable increase in mean PGHC 8.83 $\pm 2.79 \mathrm{mIU} / \mathrm{L}$, but this increase in GHC was not considerably vary from that at 0 minute $(\mathrm{P}>$ 0.1). Ten adult male volunteers were administered $5 \mathrm{mg}$ melatonin by [21] at about $4 \mathrm{pm}$ and studied growth hormone concentration over 24 hours after treatment. They did not find any effect on GHC (P>0.05), however they found time dependent effect of melatonin on GHC $(\mathrm{P}=0.01)$, which was high at night but did not find any interaction between time and melatonin. They have also showed that basal growth hormone levels in these subjects were $3.4 \pm 1.3 \mathrm{mU} / \mathrm{I}$ after plecboand $5.3 \pm 2.4 \mathrm{mU} / \mathrm{I}$ after melatonin administration. The present study also indicates that $5 \mathrm{mg}$ melatonin elevates the growth hormone concentration after 15 minutes to 30 minutes $8.71 \pm 2.81$ $\mathrm{mIU} / \mathrm{L}$ and then decreased.

Administered $12 \mathrm{mg}$ oral melatonin to seven normal human subjects in the afternoon at 2:30 to $3 \mathrm{pm}$ [22]. They choose this period of the day because biological systems are most 
sensitive to melatonin in the afternoon [23]. Samples were taken after every 15 minutes interval from 0 to 180 minutes. At 0 minute melatonin was administered and found increase in growth hormone level at 30 minutes and peak at 45 minutes. Growth hormone decreased suddenly from 45 to 90 minutes and then remained normal from 90 minutes to 180 minutes. In this study also melatonin caused maximum increase in growth hormone concentration after 15 minutes $8.83 \pm 2.79 \mathrm{mIU} / \mathrm{L}$ which remained high upto 30 minutes. The result reveal that melatonin in monkey has an effect on elevation of growth hormone. It might be possible that melatonin in Rhesus monkey stimulates growth hormone secretion at hypothalamic level.

Meeking examined the oral melatonin $(5 \mathrm{mg})$ effect on exercise induced growth hormone secretion in seven healthy male subjects having BMI (body mass index) of $23.9 \pm 0.9$ $\mathrm{kg} / \mathrm{m}^{-2}$. Subjects studied on two circumstances, receiving either melatonin or placebo in random order. The duration of each study was 180 minutes and began at $1400 \mathrm{~h}$ [24]. Zeman demonstrated that a single melatonin injection was able to affect growth hormone secretion in Japanese quail [25] and in man by [15]. This increase in growth hormone concentration was time dependant, it started increasing from 0 to 20 minutes time and it was highest at 40 minutes and then decreased to 60 minutes, where as in present study oral melatonin administration has increased growth hormone concentration for short time and then decreased with the passage of time which shows time dependant effect in adult male monkeys.

\section{Conclusion}

Present study supports that melatonin sharply increases plasma growth hormone concentrations for short time and then starts decreasing. Consequently results in significant decrease in growth hormone with increase in time. Thus, it shows the time dependent effect of melatonin on plasma growth hormone concentrations.

\section{Authors' contributions}

Conceived and designed the experiments: GJ Kanhar, Performed the experiments: GJ Kanhar, Analyzed the data: S Soomro, Contributed materials/ analysis/ tools: GJ Kanhar, Wrote the paper: S Soomro.

\section{References}

1. Karasek M \& Kinczyk K (2006). Melatonin in humans. $J$ Physiol and Pharmacol 57(5): 19-39.

2. Lerner AB, Case JD, Takahashi Y, Lee TH \& Mori N (1958). Isolation of melatonin, pineal factor that lightens melanocytes. J Am Chem Soc 80: 2587.

3. Lerner AB, Case JD \& Heinzelman RU (1959). Structure of melatonin. $J \mathrm{Am}$ Chem Soc 81: 6084-6085.

4. Reppert SM (1997). Melatonin receptors: molecular biology of a new family of $G$ protein coupled receptors. J Biol Rhy 12: 528-531.

5. Vanecek J (1998). Cellular mechanisms of melatonin action. Physiol Rev 78: 687721.

6. Arendt J (1998). Melatonin and the pineal gland: influence on mammalian seasonal and circadian physiology. Rev Reprod 3: 13-22.

7. Reiter RJ, Chen LD, Poeggeler BH, Barlow-Walden L, Sewerynek E \& Melchiori D (1996). Antioxidant actions of melatonin and related compounds. In Handbook of Antioxidants, E Cadenas, L Packer (eds). New York, Marcel Dekker. 513-541.

8. Gupta D \& Attanasio A (1988). Pathophysiology of pineal function in health and disease in children. Pineal Res Rev 6: 261- 300.

9. Gupta D, Riedel L, Frick HJ, Attanasio A \& Ranke MB (1983). Circulating melatonin in children: In relation to puberty, endocrine disorders, functional 
tests and racial origin. Neuroendocrinol Lett 5: 63-78.

10. Waldhauser F, Boepple PA \& Cowley WFJr (1991). Low nocturnal serum melatonin levels in precocious puberty. Adv Pineal Res 5: 329-331.

11. Aleandri V, Spinal V \& Morini A (1996). The pineal gland and reproduction. Human Reprod 2(3): 225-235.

12. Hadley ME (2000). Endocrinology. Prentice-Hall, Inc., Upper Saddle River, New Jersey.

13. Wright J, Aldhous M, Franey C, English J \& Arendt J (1986). The effects of exogenous melatonin on endocrine function in man. Clin Endocrinol 24: 375-382.

14. Lissoni P, Resentini $M$ \& Mauri $R$ (1986). Effect of acute injection of melatonin on the basal secretion of hypophyseal hormones in prepubertal and pubertal healthy subjects. Acta Endocrinolica 111: 305-311.

15. Esposti D, Lissoni P, Mauri R, Rovelli F, Orsenigo L, Pescia S, Vegetti G, Esposti $G$ \& Fraschini F (1988). The pineal gland-opioid system relation: Melatoninnaloxone interactions in regulating $\mathrm{GH}$ and $\mathrm{LH}$ releases in man. $J$ Endocrinol Invest 11: 103-106.

16. Attanassiou A, Bombelli M, Kuzmanovic D \& Gupta D (1986). The pineal; influence on growth hormone secretion. Neuroendocrine Lett 8: 275-282.

17. Vriend J, Sheppard MS \& Borer KT (1990). Melatonin increases growth hormone and insulin-like growth factor I (IGF-I) levels in male Syrian hamsters via hypothalamic neurotransmitters. Growth Develop and Aging 54: 165-171.

18. Haigh VM \& Scott A (1965). Some radiological and other factors for assessing age in the rhesus monkey using animals of known age. Lab Anim Care 15(1): 57-73.
19. Rizvi SSR, Weinbauer GF, Arslan M, Partsch CJ \& Nieschlag N (2000). Testosterone modulates growth hormone secretion at the hypothalamic but not at the hypophyseal level in the adult male rhesus monkey. J Endocrinol 165: 337344.

20. Rizvi SSR, Altaf S, Latif S, Naseem AA, Afzal M Qayyum M (2004). Chronic orchidectomy does not influence the sensitivity of the pituitary somatotropes to varying doses of GHRH administered intravenously to the adult male rhesus monkey. Life Sci 75: 1041-1050.

21. Kostoglu-Athanassiou I, Treacher DF, Wheeler MJ \& Forsling ML (1998). Melatonin administration and pituitary hormone secretion. Clin Endocrinol 48: 31-37.

22. Coiro V, Volpi R, Capretti L, Giuliani N, Caffarri G, Colla R, Marchesi C, Chiodera R (1998). Different Effects of Naloxone on the Growth Hormone Response to Melatonin and Pyridostigmine in Normal Men. Metabolism 47(7): 814-816.

23. Massara F, Ghigo E \& Demislis K (1986). Cholinergic involvement in the growth hormone releasing hormoneinduced growth hormone release: Studies in normal and acromegalic subjects. Neuroendocrinology 43: 670-675.

24. Meeking DR, Wallace JD, Cuneo RC, Forsling M \& Russel-Jones DL (1999). Exercise induced $\mathrm{GH}$ secretion is enhanced by the oral ingestion of melatonin in healthy adult male subjects. Eur J Endocrinol 141: 22-26.

25. Zeman M, Buyse J, Lamoova D, Herichova I \& Decuypere E (1999). Role of melatonin in the control of growth and growth hormone secretion in poultry. Dom Anim Endocrinol 17: 199-207. 